\title{
Living with the I-word: Improvisation and its Alternates ${ }^{1}$
}

\author{
Robert Labaree
}

\section{Introduction}

Maybe improvisation, or the I-word, as I choose to call it, causes no problems in your musical life. In my own, it is the source of daily dissonance, a major player in an often unacknowledged tug of war of meanings, musical politics, and practice within my immediate musical community. On the one hand, the frequent reliance on the I-word by conservatory colleagues-performers and music scholars who specialize in virtually any music industry category you could name-attests to its continuing resonance and convenience. On the other hand, in recent years, there is the growing sense among a much wider circle of observers, some of them on these pages (Manderson, Ramshaw), that the I-word obscures more about what musicians do and listeners experience than it illuminates. It is because improvisation is both widely used and obscure that I have taken to treating it as a four-letter word, a term demanding extreme sensitivity to context by those who would use it. Converting it to an I-bomb at least has the benefit of injecting irony into the concept (not in front of Grandma!), a first step toward a critical perspective on it. This ironic spin on the word has many applications, implying scare quotes and a parenthetical question mark (or perhaps an apologetic (:)) wherever it appears. There are moments when I find it useful to speak about how the I-concept can permeate musical conversations, making them I-conversations and converting the participants into I-people and not-Ipeople. Speaking of an I-spokesman or an I-situation or an I-predicament calls attention to the ubiquity, depth, and invasiveness of the I-problem.

In a conversation among diverse practitioners I find an uncritical reliance on the I-word troubling unless we make it our business to problematize the unquestioned polar assumptions of I-discourse: that at one end of musical practice-any musical practice - there is the iconic stable and replicable musical object which is either scored or memorized, and at the other, the equally iconic on-the-spot creation of specialist I-people playing without a score. Looking across the divide between these two branches of human experience can evoke on either side a kind of melancholy longing for a road not taken. Standing with the not-I-people, the creations on the I-side look like the very definition of freedom (though admittedly with a hint of musical license or indiscipline). Standing with the I-people, the creations on the not-I-side seem attractively authoritative and substantial (though perhaps with a hint of bourgeois bleakness, suggesting a life of colouring within the lines).

It is the durability of this cartoon of a rigidly balkanized musical culture that interests me, but not only because it fails to capture much of the complexity and dynamism of in-the-flesh music-making. The cartoon also interests me because it persists in the face of several generations of scholarship and reflection on l-issues, which have done a lot of the work of problematizing the I-concept for us. For example, after fifteen years the collection of essays edited by Bruno Nettl and Melinda Russell in 1998, In the Course of Performance, is widely-read and often-cited, but remains a witness to how much of its content is still unabsorbed into general discourse. Although the word improvisation appears on nearly every page of the volume (unlike this essay), the total effect of the accumulating conversation among specialists in diverse traditions_-including Indonesia, nineteenth century Germany, North and South India, medieval Europe, Egypt, China, jazz, Aboriginal children's songs and African-American dance songs-is that much of the fog and burden of the I-word is gradually lifted. In such a context, we find ourselves able to do what was much less possible even twenty-five years ago: we can begin to imagine a homely and workaday place for the whole complex of I-notions in a twenty-first century definition of-what else can we call it?-musicianship. As an aspect of musicianship, the I-word might even re-connect to its roots in general European music-making before the midnineteenth century, when the current I-paradigm was cast in bronze. (About this important historical shift more will be said presently.) Musicianship is a value which all musicians can respect, I-people as well as not-I-people, because it is a word which stands for what musicians are expected to be able to do. But a discussion of what constitutes musicianship is different from a discussion in which, for example, "improvisatory" functions as a marker for what is free, irrational, or otherwise unexplainable in musical experience.

In the hope that the difficulty with the I-word might turn out to be its greatest contribution, I will be offering here, for the sake of argument, some alternate concepts, beginning with the word musicianship itself. The definition of each new term and its particular contribution to this exercise will gradually emerge through examples in distinct repertoires. These repertoires have been chosen for the very reason that they rarely attract the I-word. Reflex l-genres like jazz, free jazz, and free improvisation will play no more than cameo roles here, forcing us to look for l-qualities where we least expect to find them and thus to re-examine our dependence on those benchmark categories in our thinking about the full spectrum of music-making. Nettl modestly encapsulated this full spectrum and the different forms it takes across cultures and history in The New Harvard Dictionary more than two decades ago: "It seems most appropriate to reserve the term improvisation for cultures and repertories in which a distinction from non-improvised 
and pre-composed forms can be recognized" (392). That very distinction-a cardinal feature of what I am calling the nineteenth century I-paradigm —was finally frozen in place in the world of schooled music-making in the West during the twentieth century, with jazz and European concert music playing the roles of mutually defining other, the poster children of the I- and the not-I-identities.

A caution: none of the alternates for the l-word offered here, beginning with "musicianship," should be taken as synonymous with the one-size-fits-all "improvisation." Rather, I see these alternates as facets of the I-word's legitimate content (to give the concept its due), the content which is too often obscured when we default to I-speak because it appears to fill a musical-existential void when we need it.

\section{Variability and Control in the Poetics of Chopin}

With the idea of musicianship already on the table, let me offer two more alternates before turning to examples: the word variability and the word control. What these two concepts bring to a musical discussion as I-alternates is best demonstrated by beginning at the heart of the European classical canon, where the I-word seldom makes an appearance. Consider the studies of variability and performer control in the piano music of Frederic Chopin by Leo Treitler, Nicholas Cook, Jonathan Bellman, and Jeffery Kallberg. These are all examples of what Cook calls "musicology's faltering advance towards a performance studies paradigm" ("Between Process" 13), a paradigm in which acoustic events are as central to music scholarship and pedagogy as scores. For our purposes here, we might keep the performance studies paradigm in mind since it suggests at least one possible way across the chasm between the I-identity (normally focused on live events) and the not-l-identity (normally focused on replicating what is written).

Treitler looks at early recorded performances of Chopin's published waltzes and mazurkas by nineteenth century pianists who lived into the recording age ("Early Recorded Performances"). Comparing Treitler's transcriptions of these performances with their scores, the polymorphousness of Chopin's pieces-featuring the doubling of written passages in thirds, sixths, or octaves; the substitution of chromatic passages for diatonic ones; the free ornamentation of melodic lines; the extension of passages with additional measures; the alteration of harmonies, rhythms, and accompaniments; change in the order of certain measures; the lengthening of introductions and cadences-calls attention to how each performer felt empowered to assert control over what he or she was given. Treitler found such examples of variability in these recordings "too numerous to itemize" (65). ${ }^{2}$

Example 1 from Treitler's study shows samples of how Josef Hofmann (1876-1957) in 1922 chose to vary the actual harmonies and voicings in the left hand of the "Waltz in C\# minor Op. 64, no. 2," as compared with the published score (see below for discussion of similar variants in Chopin's own drafts in Kallberg's "Chopin 'Problem'”).
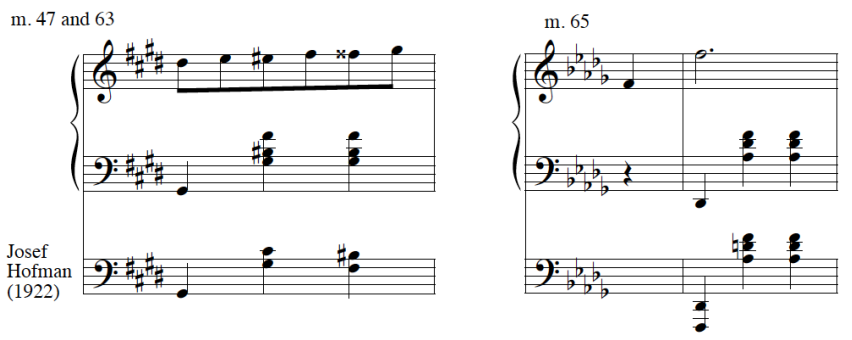

Example 1: Josef Hofmann's variants in the left hand of Frederic Chopin, "Op. 64, no. 2" (1922), compared with standard score (Treitler, "Early Recorded Performances" 64).

Example 2 is from Bellman's study of "Chopin and His Imitators," an excerpt from a published "Homage à Chopin" by Pierre-Joseph-Guillaume Zimmerman (1785-1853), head of the piano department at the Paris Conservatory, Chopin's next-door neighbor, and author of L'Encyclopèdie du pianiste compositeur (Paris, 1840). Assuming the role of pedagogue, Zimmerman provides an extra line of music to demonstrate how a pianist in the Chopin style would ornament a lyrical line over a steady accompaniment. 


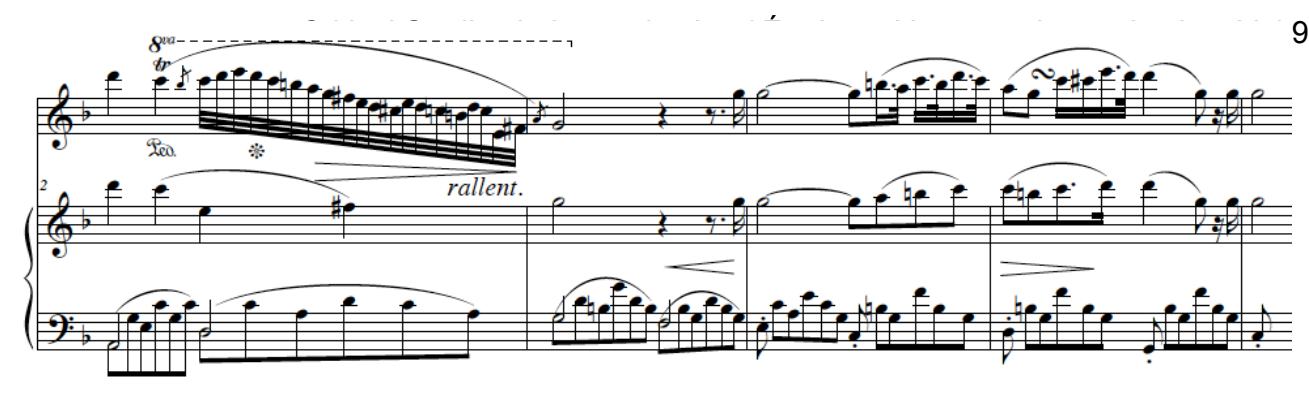

9, No $2(2013)$

Example 2: Pierre-Joseph-Guillaume Zimmerman, Nocturne Op. 21, mm. 19-32 (1840) (Bellman 159).

Cook's discussion tightens the focus even further on tempo and rubato ${ }^{3}$ by plotting performance tempos on a graph illustrating the wide distribution of treatments. Very likely, it is against this array of aural experiences, and not the score, that musicians and listeners actually hear any given performance. If they find Paderewski's rendition hurried or his rubato excessive, it may be that they have in mind the rendition by Horowitz. More importantly, these may even suggest that, far from being an aberration, the range of variability highlighted in these studies was expected by audiences of the day. This is what Treitler concludes, interpreting these variant versions as signs of poesis, from the Greek poiein, meaning to do or to make, a word I would add to our growing list of I-alternates ("Early Recorded Performances" 55). The variable performances of these notated pieces provide a glimpse of a performance poetics, that is, a glimpse of music being made according to prevailing standards of aesthetics and musicianship. In contrast to the range of early twentieth century variability in the Treitler study, the distinctive features of, for example, Garrick Olson's performances in 1996 (Arabesque), are limited to micro-rhythm, tempo and dynamics. Such comparisons are of interest to us all, whether or not we are I-people, since they are clues to at least one feature within the spectrum of Western musical poetics: that in late twentieth century art music piano performance there is less tolerance of variability and performer control than just fifty years earlier.

Chopin's own rendering of many of his compositions was as variable as the early twentieth century performances Treitler examined. Over the years, many pieces take a multiplicity of forms in drafts, presentation copies, and published scores-sometimes printed with the composer's approval by different publishers in the same year (Kallberg, "The Chopin 'Problem'” 215-228). Kallberg's comparison of variability of the left-hand accompaniments in Chopin's various drafts of the Waltz Op. 64 no. 1 ("Variants" 362) resembles Treitler's comparison of Josef Hoffman's 1916 performance of Op. 64 no. 2 with the published score in Example 1 above. This variability in Chopin's paper trail is well known but it is often interpreted narrowly - as a sign of his composerly perfectionism, his tireless search for the final rendering of a musical idea. For Kallberg, the variability is a more general sign of how "composers, no less than poets, novelists, and painters in the nineteenth century, embraced a fluid conception of the work of art" ("Variants" 267). José Bowen (citing Carl Dahlhaus a generation earlier) takes a further step, urging that Chopin be understood within a spectrum of period variability: "Nineteenth-century musicians did not have a single aesthetic consciousness: composers like Rossini (from the opera-dominated South) continued to create unique musical events, while composers like Beethoven (from the symphonic-dominated North) began to create more permanent, fixed musical works, with composers like Liszt and Chopin usually somewhere in between" (429). These statements are of interest to I-people, not-I-people and audiences equally, since they direct our attention toward the degree of mobility in musical events which listeners and musicians in a particular historical context are willing to accept.

In the end, the I-concept cannot do justice to the full range of variability in Chopin's legacy. Kallberg notes that Chopin did a lot of the work of composing at the piano, so that his written sketches tended to represent what he had discovered in performance. ${ }^{4}$ Chopin's students testify to how his own performances of his pieces often departed from what he had written and from his annotations in personal scores of them (Kallberg, "Variants"). Then there are the contemporary accounts of Chopin's performer-generated compositions before an audience. Julian Fontana, the composer's lifelong friend, considered that "Chopin's most beautiful finished compositions are merely reflections and echoes of his improvisations," one version of the I-perspective in Western art music which legitimizes extempore composition as a preliminary stage to the fixed composition. Another friend, Wojciech Grzymała, observed that "Chopin's improvisations were far bolder than his compositions," leading the painter Delacroix to liken improvisation to the preliminary sketches for a painting. But Chopin's student Karol Mikuli stressed that Chopin had "a memory as highly developed as it was reliable," and that he had at his fingertips a large repertoire of pieces by Bach, Mozart and Beethoven, even though his concert programs mostly consisted of his own pieces. How he played these now-canonic pieces is another matter (Eigeldinger 282). Treitler recalls that Josef Hofmann argued strenuously for greater "objectivity" and "exactness" in the treatment of scores, and yet his $78 \mathrm{rpm}$ performances of Chopin and others belong at the opposite end of the variability spectrum from Garrick Olsen's ("Early Recorded Performances" 65-66). Add to this Chopin's legendary agonizing over the details of his written compositions and we complete the outline of his legacy in full array. At no point in this spectrum of variability can we confidently say, "Here is the place where composition ends and improvisation begins." If this is how Chopin's music was conceived, received, and transmitted for more than a century, what is gained by assigning the word "improvisation" to any instance of variability in this 
spectrum as though it were a special case, the exception to the free-standing musical object?

These Chopin studies remind us of what is often sidelined in polarized I-conversations: that in classical music, replication of the score is paramount, but that robotic replication of scores is anathema (What is the worst thing you can say about a performance of a Beethoven sonata? "That was beautiful! It was just like the score!"). In the performance of classical canonic texts, variability is still important. The fact that some kinds of variability are writ larger in one period than another-that variability itself is variable-is part of the general musical background against which any use of the I-word must be understood.

\section{Musicianship and Mouvance in Troubadour Song and Folk Song}

With these observations of Chopin as background, consider the use of the I-word in the study of a European repertoire less central to the art music canon: secular song of the middle ages. Beginning in the 1960s, the scholar Hendrik van der Werf was the first to view the different versions of the same song in different manuscripts of the troubadour and trouvère repertoires as signs that the songs were the product of an oral culture. The variability among these versions of monophonic songs covers a wide spectrum, as example 3 shows ${ }^{5}$ (only three lines of the song are shown here).

These three versions of the song "Be.m pac d'ivern e d'estieu" attributed to Piere Vidal (late $12^{\text {th }}$ century) were written down a generation or two on either side of 1300 by scribes trained in the monastic tradition of sacred monophonic chant. As in the nineteenth and twentieth century Chopin examples (performed and written), these fourteenth century variants, taken together, have enough in common to establish a common identity, though they are also extremely fluid in their details.
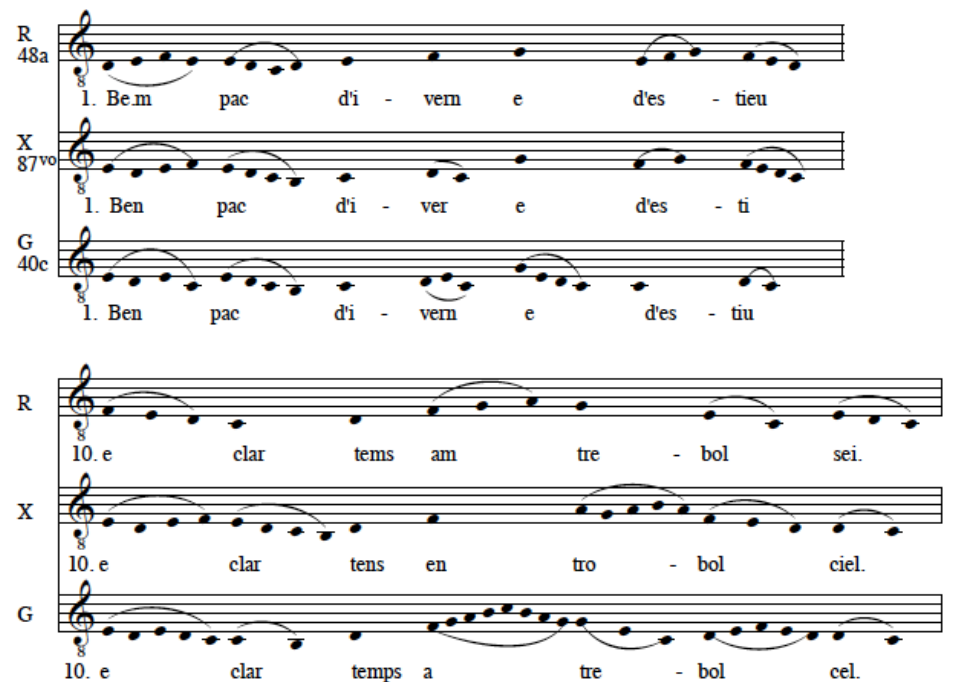

Example 3: Peire Vidal, "Be.m pac d'ivern e d'estieu" (late $12^{\text {th }}$ c.).

Lines 1, 3, and 10 as they are found in three different manuscripts (van der Werf, The Extant Troubadour, 239*$\left.242^{*}\right)^{6}$

Example 4 focuses on the variability within three versions of just the first four lines of Gaucelm Faidit's "No m'allegra chan ni critz." 


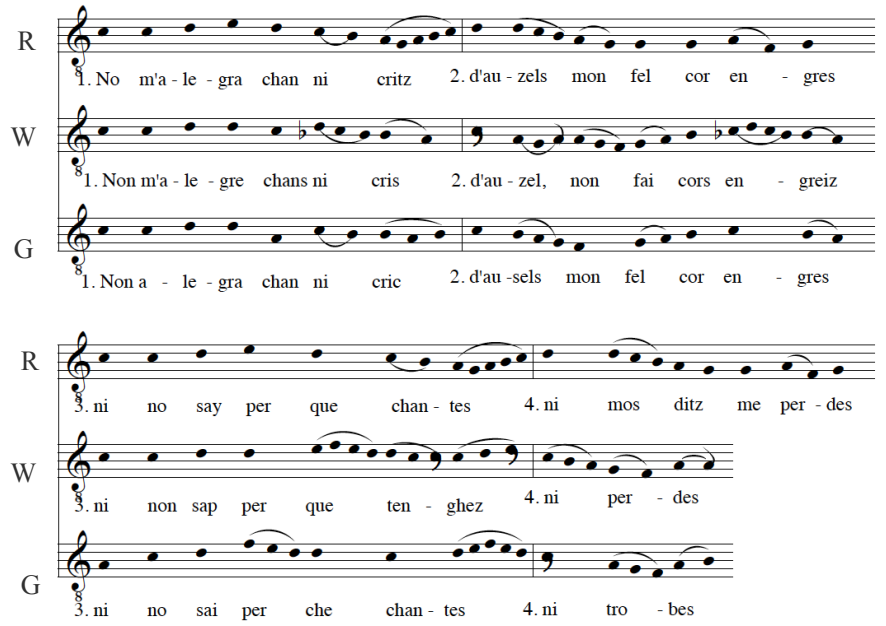

Example 4: Gaucelm Faidit, "No m'allegra chan ni critz" (late $12^{\text {th }}$ c.).

Lines 1, 2, 3, and 4 as they are found in three manuscripts (van der Werf, The Extant Troubadour 137*-140*).

The $\mathrm{R}$ ms. version exhibits the classic melodic pattern found in the first four melodic lines of many troubadour songs: A B A B. However, in the W ms. version, the internal melodic repetitions are somewhat more varied, $A B A^{1} C$, while the $G$ ms. version shows even less internal repetition, A B C D (in part, these reflect differences in the poetic texts). A comparison between these three versions suggests different positions on the spectrum of this song's variability: $G$ most approaches a through-composed form with no repetitions, while $\mathrm{R}$ is the most clearly marked by repeated material, with $\mathrm{W}$ falling between these two extremes. Unlike the Chopin examples, the presence of the performereither through contemporary testimony or through recordings-appears shadowy in these medieval examples. But Treitler, in a series of studies of medieval song, provides a conceptual bridge between early and late European examples through his view of medieval notation as a type of performance: for monastic scribes, music notation was less a prescription than "a way of exemplifying pieces, just as performing it was a way of exemplifying it" ("Transmission" 209). One way of understanding the range of variants in Examples 3 and 4, like those from the Chopin legacy, is that they express a particular cultural tolerance of variability and performer control.

Van der Werf's view of orality illuminates another limit of the I-word. He contrasts the relative sophistication of troubadour and trouvère poems on the page with their rather plain tunes: "Their poems[,]" he said, "were performed to melodies which sound to us like improvisations, while the poems themselves are sophisticated creations in carefully designed forms [...] For with notation, the musician was able to compose new, artful, and complex sentences." Here he is referring explicitly to the detailed rhythmic notations of the new polyphonic pieces which were appearing in the $14^{\text {th }}$ century, about the time that scribes were assembling these troubadour manuscripts using the older notation system of monophonic chant. Without these notational advances, he says, the troubadours and trouvères "made up beautifully flowing and charming but short and simple phrases in a traditional and conventional vein" (The Extant Troubadour 115).

This is one of the perils of I-speak, in which writing tends to act as a default benchmark. For van der Werf, "improvisation" stood for any performance which fell somewhere off the page. Oral transmission explained to his satisfaction the variability of the troubadour manuscript record, but it also inescapably implied to him a more naïve musical object. The l-word functions here as a screen obscuring unexamined beliefs about musical works, transmission, and musicianship. In this case, what is unexamined in the l-word is the assumption that artistic sophistication goes with writing and that artistic naïveté goes with orality, effectively answering potential questions before we have a chance to ask them. There is also a more sinister and long-term effect here: I-talk of this kind gives support to the notion that the written practices of Western Europe exist in a kind of Green Zone, set apart from the practices of other peoples. In Iranian ethnomusicologist Laudan Nooshin's summary of this view, "Europeans have art; others, such as Indians, have improvisation" (245).

Contrast Van der Werf's approach with that of Paul Zumthor, the French literary scholar (not a musician) who also 
began his work in the 1960s and 70s with the Middle Ages. He noticed that no two manuscript versions of a given example of early French lyric poetry were ever exactly the same. With the possible exception of the first stanza, the rhyme words, and the tornada (the short final stanza), the precise composition of many poems is indeterminate. Eventually, rather than worrying about how to establish which one of the variants was the best, the earliest, or the most authentic version - this was the default scholarly method up to that time-he embraced them all and decided that it was the tendency toward variation which was important, not adjudicating the merits of each variant. His writings rarely make use of the I-word, though he did invent a useful term for the more or less constant variability he observed in poetries and rituals world-wide: mouvance (51). Zumthor also spoke of zero mouvance (203) to give a name to those many cases of cultural events where there is strikingly less tolerance for variability. I suggest that we add mouvance to our growing list of alternates to the I-word.

The special contribution of mouvance to what would otherwise be an I-discourse is its presumption that conversations about music begin and end with events rather than objects. Cook formulates this as an emphasis on process rather than product and sees it as an aspect of the performance paradigm ("Between Process"). Oriented to mouvance, variation becomes the default rather than the exception, and music is allowed to remain in motion as we attempt to catch up with it. This can be an unsettling situation in which musicology takes on some of the qualities of field work. But it also allows us to remain within the ephemeral realm where music is actively made, encouraging us to stay focused on the details of musical behavior within a particular habitat. In this way we may find ourselves less compelled by, for example, claims that (echoing van der Werf) a particular improvisation is so well-made that you might even think it was a composition, as some writers on jazz improvisation have suggested (Schuller).

Folk music may be considered the poster child of Zumthor's mouvance phenomenon and further illustrates the Iword's dependence on a misconception of orality. In the study of both folk music and folk tales since the early nineteenth century, many scholars and collectors have tended to treat variability as an irritant, a flaw in the perfect body of a presumed work of literature or music. Using approaches modeled on those of medievalists, classicists and biblical scholars before them, most folk song collectors until the middle of the twentieth century began their work by first eliminating most of the troubling variants created by musicians of the past by dismissing them as the products of illiteracy, by dismissing all but the "best" of the variants, or by reducing all variants to a hypothetical progenitor of which the variants were presumed to be corruptions. From this point of view, if a particular version was considered especially worthy, it could be explained as one Scottish collector, William Stenhouse, did in 1853: "Some early minstrel, or musical shepherd, composed the simple air; which being picked up by the learned musician, took the improved form it bears" (qtd. in Shapiro 13). With the question of variants thus resolved, scholars could settle back into the comfortable schema which placed replicable, notated, and authored musical texts at the center of the musical solar system-like the geocentric universe before Copernicus.

Example 5 emphasizes a different segment of the mouvance spectrum, the range of variability which occurs in the course of multiple repetitions of a tune in the hands of a single dance fiddler. In Linda Burman's transcription of a 1926 performance of the Appalachian fiddle tune "Sail Away Lady" by Uncle Bunt Stephens $(51,62-68)$ the variations are systemic but subtle, perhaps too subtle to qualify for the standard-issue definition of improvisation (a comparable transcription of a Beethoven sonata performance would likely reveal a similar level of variability). But the importance of the I-benchmark here is overshadowed by what these miniscule variants tell us about prevailing standards of musicianship and audience expectation, features of the poetics of 1920s Appalachian fiddle performance.

The American folk song collector Gavin Grieg eloquently expressed the richness of folk song variability without a hint of the l-concept in 1963:

These endless variants [...] are apt to become the despair of the conscientious collector. He cannot take one version and say he has the tune, so long as there are other versions in vogue. He must have all he can get. But then where is the tune? What is it? [...] In despair he falls back on a kind of intuition, through the exercise of which he feels that his ruck of records are all variants of something which is at once the air and in it. (qtd. in Cowdery, "Rethinking" 4) 

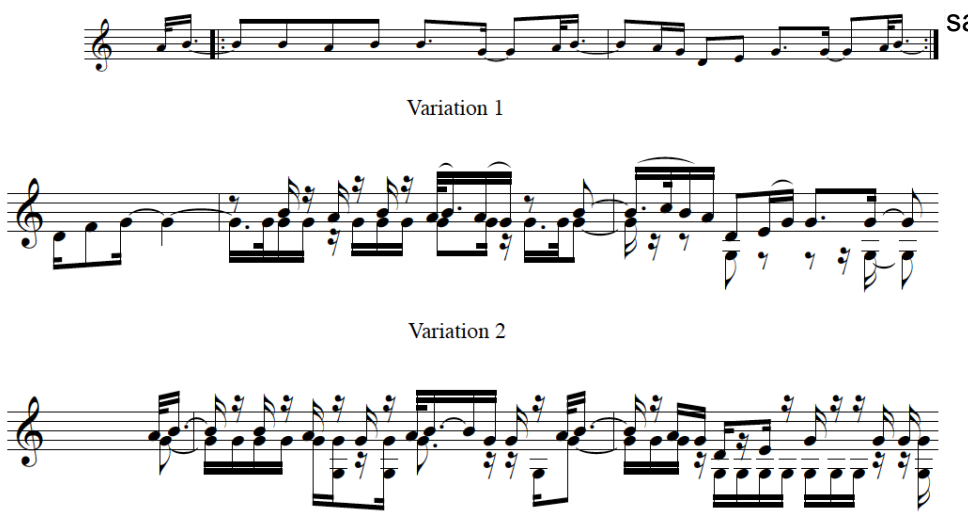

Example 5: Uncle Bunt Stephens, "Sail away lady” fiddle variations (1926) (Burman 51, 62-68).

I admire how Grieg would rather remain uncertain about the musical object of his study than be distracted from his elusive goal- -the discovery of "something which is at once the air and in it." What a phrase! Coming from such a close observer of folk singers at work, these words challenge us to imagine an identity for a piece of music which is both a single thing and the sum of its variations, both current and future. Through Grieg's eyes we may be able to catch a glimpse of life without the dualism imbedded in the I-categories, a space where we can embrace musical entities which are dynamic and continually in the making. This is a region where variability is not simply a negation of fixity, but a given, a constant, like mass or gravity, recognition of which permits us to be comfortable with music as a negotiation for control of the event, as poesis.

It took several generations of investigations before a mature notion of "tune family" was evolved by ethnomusicologists like James Cowdery which could begin to describe the principles of variability in oral composition. Cowdery called the constructive principles he observed in the variant versions of Irish folk song "outlining," "conjoining," and "recombining" (Melodic Tradition 43-133). A generation before him, Albert Lord, the great student of variant versions of sung epic poetry in Yugoslavia, had resorted to the notions of "formula" and "theme" to account for how an illiterate butcher from the mountains of Bosnia-Herzegovina could create with voice and two-string fiddle (gusle) tightly disciplined and rhymed verses totaling the length of the lliad before a coffee house audience on successive nights in the month of Ramadan. Lord recalls how, on one occasion in the 1930s, the epic singer (guslar) Avdo Međedović waited outside the hall where another singer, Mumin Vlahovljak, was recording an epic tale of several thousand words, an epic Avdo did not know. When the first singer had left, Avdo commented that "it was a good song and that Mumin had sung it well, but that he thought he might sing it better." The result was a version considerably longer than the first (Lord 78). Neither Lord, nor Cowdery, nor Zumthor felt the need to resort to the Iword. Their focus remained on live events, on discovering the constructive principles employed by the agent in control of the music and the poetry.

\section{I-problems are Everyone's Problems}

The discomfort of folk music collectors with "these endless variants" has an important corollary: the inability or unwillingness of many folk performers to acknowledge variability at all, while at the same time their language remains strikingly free of anything like I-references. Indeed, it is a commonplace of folk song collecting that informants will often seem baffled when asked to reflect on or even acknowledge the obvious variants in their own performances or in those of others. In 1907 Cecil Sharp described performers in the English countryside in this way: "I have never met a singer who could detect small melodic differences. So long as your tune is, in the main, similar to his, the most musical of folk-singers will declare it to be identical, although the differences may be of considerable importance from a musician's point of view, e.g., a change of mode or a variation in rhythm" (Sharp, Karpeles, and Williams 16-17).

Such observations by fieldworkers demonstrate that, for folksingers, the tendency or even obligation to vary is folded into their definition of musicianship, and therefore drops out of sight into background. That definition of musicianship often does not distinguish sharply between fixed and variable performance, let alone between composition and improvisation. Once again, this would also describe aspects of Western art music performance in (to take just one example) Vienna at the time of Mozart, when what appears to us like I-skills-for instance, the habitual variation of music between repeat signs-were assumed. They were skills which were not normally made explicit except at those moments when a musician would step into the role of teacher. Most of what we know today about these early European art music practices is drawn from manuals, treatises, and specially-prepared scores which are pedagogical in intent, like the Zimmerman excerpt in Example 2. The pieces published in E.T. Ferand's indispensable collection, Improvisation in Nine Centuries of Western Music (1961), are largely drawn from just such sources. 
A final Turkish illustration demonstrates how different histories generate different negotiations with variability, further diminishing our faith in the usefulness of the l-concept across cultures and histories. Contrary to what happened in Europe between the seventeenth and twentieth centuries, the monophonic Ottoman Turkish makam tradition in the same period did not develop a generic l-concept and a division of labor between performing and composing specialists. Turkey also did not begin the wholesale conversion of its repertoire to notation until the early twentieth century. Nor can we observe a tendency to develop a separate class of Turkish I-specialists, as in jazz. Between performer-controlled forms and fixed forms in Turkey there remains a kind of equilibrium no longer found in the practice of Western art music. Thus, the default definition of Turkish musicianship today is closer to the definition of European musicianship before 1825 when basso continuo was still the default pedagogy, when it was expected that musicians would never play the same notated section of a piece the same way twice, when preluding and the making of cadenzas were expected of all soloists, and when it was normal to ornament melodic lines and to paraphrase and rearrange the music on the page to fit circumstances. (Of course, these came with a corollary expectation that a musician would judge the circumstances and understand the type and degree of variability that was appropriate. ${ }^{7}$ As Leopold Mozart declared in 1756, it was considered poor taste for orchestral violinists "to be continually introducing details of their own invention and to regard themselves alone, paying little regard to others" [124-125]). In Turkey today, musicians are still expected to play performer-controlled taksim alongside composer-controlled beste. In the current pedagogy of taksim, students are expected to imitate the taksims of mature musicians (both live and in recordings), but also to memorize existing compositions by master composers.

Beste and taksim do not fit comfortably into current I-conversation in part because performance of Turkish compositions requires a degree of performer control and an overall acceptance of mouvance that would be more at home with Treitler's early twentieth century Chopin performers than with the finalists in today's international Chopin competitions. Turkish performers worry about getting the details of a given beste right, but each of them is also expected to individualize it. Example 6 is a transcription of an excerpt from a performance of a canonic eighteenth century instrumental piece (saz semaisi) by a renowned Istanbul duo in 2001 . The transcription compares the standard notation of the composition with a single example of how the two performers treat the composition's refrain section (teslim). Throughout the performance, each player's part is full of long sustained notes, connective passages, rests, ornaments, ghosted notes, anticipations, octave transpositions, elaborations, rhythmic variants, and dynamic changes not found in the other player's part. The impression of these variant renderings is reminiscent of what Cowdery, Lord, Zumthor, Treitler, Cook, and Kallberg also found: a pervasive sense of mutual identity amid a shimmering variability of detail.
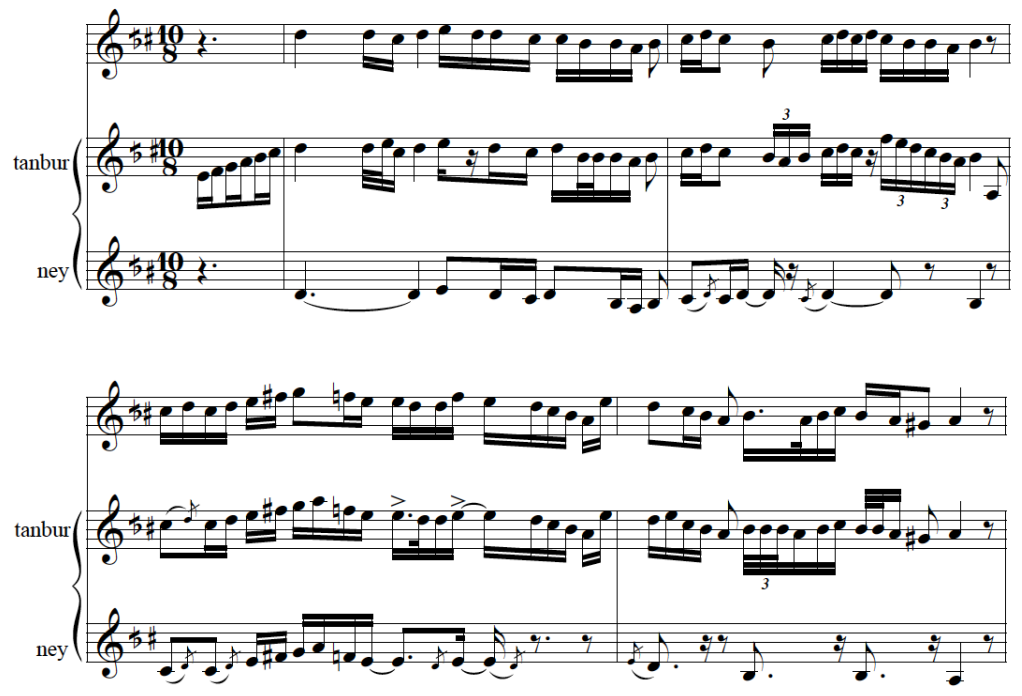

Example 6: Veli Dede (d. 1768), Saz Semaisi in Hicaz-Hümayun Makam, as played by Salih Bilgin, ney and Murat Aydemir, tanbur (2001).

Beste and its verb form bestelemek appear to lend themselves to the more generic usages of "composition" and "compose" in European languages. But the fact that "taksim" has none of the generic applications of "improvisation" suggests that beste-taksim is not a comfortable equivalent of composition-improvisation. In the Ottoman makam tradition, taksim is, like improvisation, a performer-generated form, but taksim can only be in free rhythm, probably a legacy of centuries of association with koranic chant (qir'ah), the kaside of Sufi devotional music, and the secular 
gazel, all of them vocal forms which are also invariably in free rhythm (Feldman). Taksim is too tied to a particular historical model, and therefore perhaps too indelibly Turkish to match the universal pretensions of the I-concept, making taksim in meter (usulde taksim), for example, an oxymoron and the occasion for head wagging among many Turkish classical musicians. This has not stopped some twentieth century Turkish musicians from attempting to mainstream their tradition in Western discourse by creating a new generic Turkish verb, emproviz etmek, and noun, emprovizasyon. ${ }^{8}$

\section{Conclusion}

Ambiguity in the objectness of each of these musical examples is inescapable, expressed in a variability of details which runs from the obvious to the hyper-subtle. Members of a particular tradition, committed to preserving a status quo conception of fixity and flexibility for their respective communities, can be expected to interpret the ambiguity of their musical practices narrowly. But for culturally and historically aware practitioners and scholars these ambiguities are surely worth the trouble of dragging them into view from the recesses of each tradition, since doing so provides access to the living poetics of each situation. Once we have allowed ourselves to accept the full spectrum of mouvance in the legacy of Romantic pianist, makam musician, epic singer, or medieval troubadour-explicit and implicit, performed, written, published and observed-we will be able to break the spell of the unambiguous musical object which compels us to leave a place in any conversation for its unquestioned opposite: improvisation. This is a spell which can enthrall I-people and not-I-people equally. It is the invisible puppeteer of many musical conversations. Zero mouvance may be more central to some musical circumstances than to others-to Chopin's Piano Concerto more than to his mazurkas, for instance, or to a beste more than to a taksim. Certainly, it is also no surprise if predominantly monophonic oral traditions like my Irish, troubadour, and Turkish examples are more variability-tolerant than traditions founded on a harmonic grid embodied in an 18-stave score. The historical dimension of the Ipredicament in the West is most easily traceable in an increased investment in multi-part works notated in great detail. But with variability the center of gravity, the object of study is no longer presumed to be an object, carefully barricaded from the vagaries of I-activity. By keeping a mazurka, troubadour song, or saz semaisi in motion as we take it in-as an event, as a text, and as a conception-we may find ourselves experiencing something being crafted before our eyes, even though the crafting may have happened in performance or in writing a long time ago. ${ }^{9}$

We may utter the I-word in discussing aspects of all these examples-for most of the scholars featured in this essay (not to mention the musicians themselves) the word is not central-but if we did, what would it contribute that a focus on musicianship, variability, control, or poetics does not-except perhaps the reassuring certainty of the l-zone itself? For those of us who are the direct heirs of the nineteenth century European investment in the musical object, the ability to live outside of the I-dualism also offers an added benefit: a surprising feeling of kinship with musical traditions outside of our self-imposed Green Zone. Confronted by variable renderings in music of all kinds, we need to talk about them all with the same language-if, that is, we intend to do more than simply confirm their places on one side or the other of the eternal I-divide.

\section{Notes}

${ }^{1}$ Aspects of this paper were presented in earlier form at the Conference on Improvisation in Cross-Cultural Context at Northeastern University, Boston, Massachusetts, March 18, 2011 and at the conference on Text, Media, and Improvisation at McGill University, Montreal, Québec, Canada, June 21-22, 2008.

2 Treitler's list of performers whose early cylinder and disc recordings have been digitally remastered includes: Camille Saint-Saens (1835-1921), Raoul Pugno (1852-1914), Ignaz Paderewski (1860-1941), Ferruccio Busoni (1866-1924), Josef Hofmann (1870-1956), Sergei Rachmaninoff (1873-1943), Alfred Cortot (1877-1962), and Mischa Levitski (1898-1941).

${ }^{3}$ See José Bowen (434-437) on tempo variability and rubato in all available recordings of Beethoven's Fifth Symphony and in Debussy's own performance of his "La cathédrale engloutie" (439-443).

${ }^{4}$ See Samson for a fuller discussion of Chopin's sketches, fair copies, and editions (270-281).

${ }^{5}$ The sources for the three versions are: Ms. R (Manuscrit le Valliere, southern France, ca. 1300), Ms. X (Manuscrit St. Germain des Près, northern France, late $13^{\text {th }}$ c.), and Ms. G (Florence Manuscript, northern Italy ca. 1300) (Van der Werf The Extant Troubadour $239^{*}-242^{*}$ ). See Labaree for a discussion of sources (23-49), and see note on Van der Werf page numbers on page 4-5 above. 
${ }^{6}$ The asterisked numbers indicate the actual pages in the edition, as opposed to the song's number in Van der Werf's catalogue system.

${ }^{7}$ See, for example, Lohr, Ritterman, and Whitmore.

${ }^{8}$ The neologism emprovizasyon is consistent with other self-conscious Turkish adaptations of terms and practices from Europe in law, education and culture. See O'Connell for a detailed discussion of how one such term, "alla turka," was transformed in its meaning during the early $20^{\text {th }}$ century.

${ }^{9}$ Although the dualistic I-divide continues to go unquestioned in mainstream musical pedagogy and public discourse, the scholarly literature dealing with one or another aspect of the I-problem continues to grow. In addition to those already cited, see the following examples. In music theory: P. Carpenter, "The Musical Object" (1967) and M. Butterfield, "The musical object revisited" (2002); in historical musicology: J. A. Owen, Composers at Work: The Craft of Musical Composition, 1450-1600 (1997) and R. Wegman, "From maker to composer: Improvisation and musical authorship in the Low Countries, 1450-1500" (1996); in ethnomusicology: J. T. Titon, Old-Time Kentucky Fiddle Tunes (2001) and M. Perlman, Unplayed melodies: Javanese gamelan and the genesis of music theory (2004).

\section{Works Cited}

Bellman, Jonathan. "Chopin and His Imitators: Notated Emulations of the 'True Style'." 19th-Century Music 24.2 (2000): 149-160. Print.

Bilgin, Salih and Murat Aydemir. Nevâ. Istanbul: KAF, 2001. CD.

Bowen, José. "Finding the Music in Musicology: Performance History and Musical Works." Rethinking Music. Ed. Nicholas Cook and Mark Everist. Oxford: Oxford UP, 1999. 424-451. Print.

Burman, Linda C. "The Technique of Variation in an American Fiddle Tune: A Study of 'Sail Away Lady' as it was Performed in 1926 for Columbia Records by Uncle Bunt Stephens." Ethnomusicology 12.1 (1968): 49-71. Print.

Butterfield Matthew W. "The Musical Object Revisited.” Music Analysis 21.3 (2002): 327-380. Print.

Carpenter, Patricia. "The Musical Object." Current Musicology 5 (1967): 56-87. Print.

Cook, Nicholas. "Between Process and Product: Music and/as Performance." Music Theory Online 7.2 (2001). Web. 29 July 2010.

Cowdery, James. The Melodic Tradition of Ireland. Kent: Kent State, 1990. Print.

---. "Rethinking the Concept of Tune Family." Diss. Wesleyan U, 1985. Ann Arbor: UMI, 1985. Print.

Eigeldinger, Jean-Jacques. Chopin: Pianist and Teacher as Seen by His Pupils. Trans. Naomi Shohet, Krysia Osostowicz, and Roy Howat. Ed. Roy Howat. Cambridge: Cambridge UP, 1986. Print.

Feldman, Walter Zev. "Ottoman Sources on the Development of the Taksîm." Yearbook for Traditional Music 25 (1993): 1-28. Print.

Ferand, Ernest.T. Improvisation in Nine Centuries of Western Music; an anthology with historical introduction. Köln: A. Volk Verlag, 1961. Print.

Hofmann, Josef. The Complete Josef Hofmann, Vol. 4. The Acoustic Brunswick Recordings 1922-1923. VAI Audio 1047. 1994. CD.

Kallberg, Jeffery. "The Chopin 'Problem': Simultaneous Variants and Alternate Versions." Chopin at the Boundaries: Sex, History and Musical Genre. Cambridge: Harvard UP, 1996, 215-228. Print. 
---. "Are Variants a Problem? 'Composer's Intentions' in Editing Chopin." Chopin Studies 3. Warsaw: Frederick Chopin Society, 1990. 257-67. Print.

Labaree, Robert. "'Finding' Troubadour Song: Melodic Variability and Melodic Idiom in Three Monophonic Traditions." Diss. Wesleyan U, 1989. Print.

Lohr, N. Jane. "Preluding on the harpsichord and pianoforte, circa 1770 to circa 1850." Diss. University of lowa, 1993. Print.

Lord, Albert. Singer of Tales. Cambridge: Atheneum, 1968. Print.

Manderson, Desmond. "Fission and Fusion: From improvisation to formalism in law and music." Critical Studies in Improvisation/Études critiques en improvisation 6.1 (2010). Web. 4 November 2012.

Mozart, Leopold. "Essay on the Fundamental Principles of Violin Playing." Source Readings in Music History: The Late Eighteenth Century. Ed. Wye Jamison Allanbrook. New York: Norton, 1998. 123-131. Print.

Nettl, Bruno. "Improvisation.” New Harvard Dictionary of Music. Ed. Don Michael Randel. Cambridge: Belknap, 1986. 392. Print.

Nettl, Bruno and Melinda Russell, eds. In the Course of Performance. Chicago: U Chicago P, 1998. Print.

Nooshin, Laudan. "Improvisation as 'Other': Creativity, Knowledge and Power-the Case of Iranian Classical Music." Journal of the Royal Musicological Association 128 (2003): 242-296. Print.

O'Connell, John Morgan. "In the time of alaturka: Identifying difference in musical discourse." Ethnomusicology 49.2 (2005): 177-205. Print.

Perlman, Marc. Unplayed Melodies: Javanese Gamelan and the Genesis of Music Theory. Berkeley: U of California $P$, 2004. Print.

Ramshaw, Sara L. "Deconstructin(g) Jazz Improvisation: Derrida and the Law of the Singular Event." Critical Studies in Improvisation/Études critiques en improvisation 2.1 (2006). Web. 6 November 2012.

Ritterman, Janet. "Piano Music and the Public Concert, 1800-1850." The Cambridge Companion to Chopin. Ed. Jim Samson. Cambridge: Cambridge UP, 1992. 11-31. Print.

Samson, Jim. Chopin. New York: Schirmer, 1996. Print.

Schuller, Gunther. "Sonny Rollins and the Challenge of Thematic Improvisation." Keeping Time: Readings in Jazz History. Ed. Robert Walser. Oxford: Oxford UP, 1999. 212-222. Print.

Shapiro, Ann Dhu. "The Tune-Family Concept in British-American Folk-Song Scholarship." Diss. Harvard U, 1975. Print.

Sharp, Cecil, Maud Karpeles, and Ralph Vaughn Williams. English Folk-Song: Some Conclusions. Belmont: Wadsworth, 1965. Print.

Titon, Jeff Todd. Old-Time Kentucky Fiddle Tunes. Lexington, KY: UP of Kentucky, 2001. Print.

Treitler, Leo. "Early Recorded Performances of Chopin Waltzes and Mazurkas: the Relation to the Text." Journal of the American Liszt Society 51 (2002): 57-77. Print.

---. "Transmission and the Study of Music History." Symposium on Transmission and Form in Oral Tradition. International Musicological Society, $12^{\text {th }}$ Congress, 1977, Proceedings. Print. 
van der Werf, Hendrik. The Extant Troubadour Melodies: Transcriptions and Essays for Performers and Scholars. Ed. Gerald A. Bond. Rochester: Hendrik van der Werf, 1984. Print.

Wegman, Rob C. "From maker to composer: Improvisation and musical authorship in the Low Countries, 1450-1500." Journal of the American Musicological Society 49.3 (1996): 409-479. Print.

Whitmore, Philip. Unpremeditated Art: The Cadenza in the Classical Keyboard Concerto. Oxford: Clarendon, 1991. Print.

Zumthor, Paul. Oral Poetry: An Introduction. Trans. Kathryn Murphy-Judy. Minneapolis: U Minnesota P, 1972. Print. 